\title{
Adolescence and andrologist: An imperfect couple
}

\author{
Soraya Olana, Rossella Mazzilli, Michele Delfino, Virginia Zamponi, Cristina Iorio, Fernando Mazzilli \\ Andrology Unit, Department of Clinical and Molecular Medicine, Sant'Andrea Hospital, University of Rome "Sapienza", \\ Rome, Italy.
}

\begin{abstract}
Summary Objective: The aims of this research were to study: a) the prevalence of male adolescents, aged between 10 and 19 years of age, referred to our Unit for an andrological assessment; $b$ ) the reasons (stated and subsequently modified) for referral; c) the prevalence of clinically diagnosed diseases.

Materials and methods: A total of 2.855 subjects, referred to the Andrology Unit for a first examination, were retrospectively studied. For each adolescent, a medical history was taken and an andrological physical examination was carried out. Results: Prevalence was found to be 6.9\% (197/2855). Subjects were divided into two groups according to age ( $A: \leq 14$ and $B: \geq 15$ years). The original reason stated for their consultation was corrected by $11.7 \%$ of the subjects (23/197); this correction concerned almost all the Group B subjects (21/23 (91.3\%) vs $2 / 23(8.7 \%)$ of Group A; $p<0.01)$. Regarding sexual dysfunctions, a simple explanation of certain conditions reassured the subject in about $15 \%$ of the cases. Furthermore, the physical examination proved extremely useful, revealing clinical alterations in more than $60 \%$ of subjects.

Conclusions: In conclusion, to date in Italy, the prevalence of adolescents among males referred to an Andrology Unit for assessment is very low. It is important to encourage adolescents to undergo andrological examination to enable identification of reproductive function and psycho-sexual disorders.
\end{abstract}

KEY WORDS: Adolescence; Andrological examination; Prevention; Sexual dysfunctions; Varicocele; Cryptorchidism;

Dysmorphophobias.

Submitted 11 June 2018; Accepted 19 August 2018

\section{INTRODUCTION}

Adolescence is understood to be a transitional phase of growth between childhood and adulthood. The World Health Organization (WHO) defines an adolescent as being between 10 and 19 years of age (1).

In addition, studies show that only $13 \%$ of the age group in question are aware of the professional role that andrologists play (2).

Screening for teenage pathologies should be an important part of general health management. In many countries, this used to be linked to routine physical examinations associated with military service.

The abolition of compulsory military service, in Italy, has meant that an important screening opportunity has been lost and this has led to a lower level of preventive care and treatment related to male reproductive and sexual diseases (3). Undiagnosed pathologies no longer picked up by such routine screening would affect pre-pubertal, pubertal and post-pubertal subjects, and a different approach would be needed for each age range.

The reports in the literature concerning this period are not numerous and they are mainly regarding single issues (such as varicocele, infections, anatomical anomalies and pubertal delay), or they report the results of campaigns for prevention, rather than spontaneous referrals requesting a medical examination (4-11).

The aims of this work were to evaluate:

a) The prevalence of adolescent subjects in a large population of men referred to our Andrology Unit for an andrological assessment;

b) The reasons given for first referral (subsequently modified);

c) The prevalence of clinically diagnosed diseases.

\section{Materials AND METHOdS}

A total of 2,855 subjects, referred to our Andrology Unit (Sant'Andrea Hospital - "Sapienza" University of Rome) from September 2012 to December 2017 for a first examination, were retrospectively studied. For each adolescent aged between 10 and 19 years, the following were carried out:

a) a full medical history;

b) an andrological physical examination [Body Mass Index, hair distribution, scrotum, testis, varicocele (grade I-III), epididymis, penis and breast].

The diagnosis of erectile dysfunction and premature ejaculation were evaluated using the International Index of Erectile Function - 5 (IIEF-5) and Premature Ejaculation Diagnostic Tool (PEDT) questionnaires (total score $\leq 21$ and $\geq 11$ respectively). The clinical study was conducted according to the Hospital Ethics Committee Guidelines.

\section{Statistical analysis}

Continuous data were described as absolute values, mean \pm standard deviation and range. Categorical data were described as absolute, percentage frequency, and 95\% Confidence Intervals. Student t-test and Fisher's exact test were used for continuous and categorical data, respectively. $\mathrm{P}<0.05$ was considered statistically significant.

\section{RESULTS}

The prevalence of male adolescents was found to be $6.9 \%$ (197/2855). The distribution, according to age, is shown in Figure 1.

No conflict of interest declared 
Figure 1.

Prevalence based on adolescent's age. Group A: Age 10-14 years.

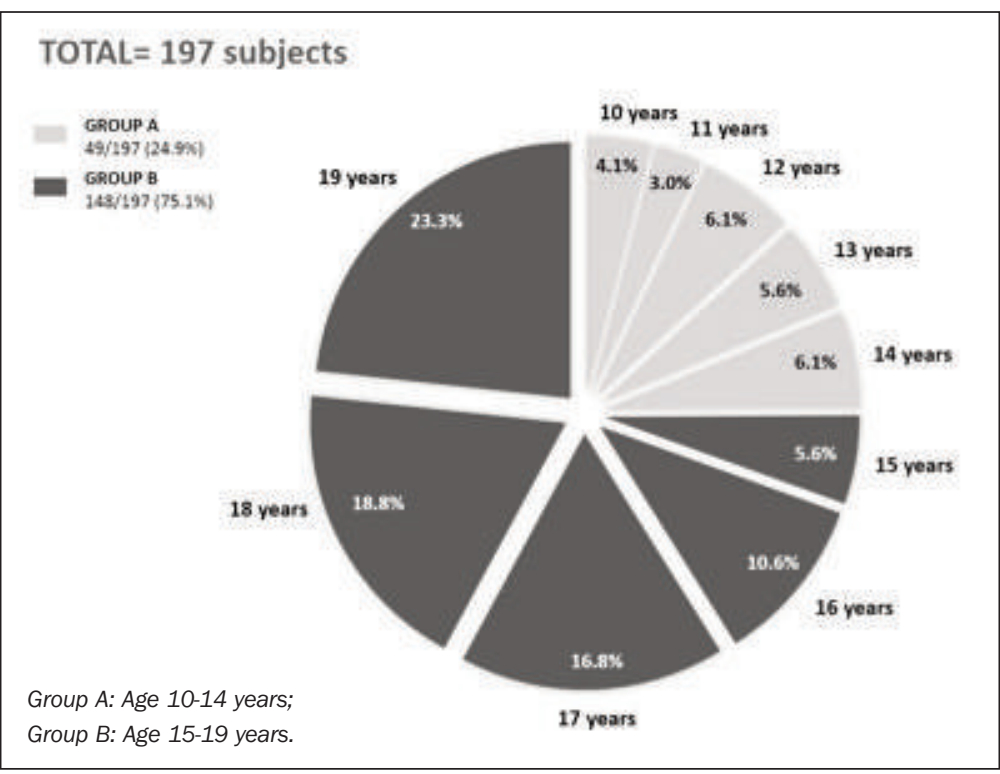

Reported and actual reasons for andrological consultation

The most common reasons given for the andrological consultation were: a preventive andrological check-up, suspected varicocele and other organic diseases.

A preventive andrological examination regarded mainly Group A (36.7\%) rather than Group B (12.2\%); p < 0.05).

While giving information for the medical history, 23/197 (11.7\%) subjects corrected the original reason stated for the consultation. This correction concerned almost all the Group B subjects $(21 / 23,91.3 \%)$ compared with a minority in Group A (2/23, $8.7 \%)(\mathrm{p}<0.01)($ Table I).

In particular, $8 / 36$ subjects, who had come for a preventive check-up, said they actually needed a consultation for sexual dysfunction. Likewise, 10/56 subjects who had initially claimed that they were worried about an organic disease, afterwards admitted that they were instead concerned about sexual dysfunction or dysmorphophobia.

According to the WHO definition, the subjects were divided into two age groups:

- Group A ( $\mathrm{n}=49$; age $\geq 10 \leq 14)$, which included subjects in pre-pubertal or peri-pubertal period; BMI $21.8 \pm 2.0 \mathrm{~kg} / \mathrm{m}^{2}$ (range 18.2-26.3).

- Group B (n = 148; age $\geq 15 \leq 19)$, which included subjects generally in the post-pubertal period; BMI $21.7 \pm 2.1 \mathrm{~kg} / \mathrm{m}^{2}($ range $18.3-28.1)(\mathrm{p}=\mathrm{NS})$.
Finally, we found that 5/9 subjects, who were initially referred to us for a suspected infection, were really suffering from dysmorphophobia or sexual dysfunction.

Clinical evidence in groups and subgroups (Table I)

1. Andrological examination: clinical alterations were observed in 17/28 subjects who originally attended for a preventive andrological examination. This concerned mainly Group A (13/18 subjects: 1/13 varicocele, 5/13 phimosis or sub-phimosis, 3/13 short

Table 1.

Referred, effective reasons of the requested of andrological examination and clinical confirmation in total and subgroups $A$ and $B$.

\begin{tabular}{|c|c|c|c|c|c|c|c|c|c|}
\hline \multirow[b]{2}{*}{ Reasons } & \multicolumn{3}{|c|}{$\begin{array}{c}\text { Total } \\
n=197\end{array}$} & \multicolumn{3}{|c|}{$\begin{array}{c}\text { GROUP A } \\
n=49 / 197(24.9 \%)\end{array}$} & \multicolumn{3}{|c|}{$\begin{array}{c}\text { GROUP B } \\
n=148 / 197(75.1 \%)\end{array}$} \\
\hline & $\begin{array}{l}\text { Firstly referred } \\
(\mathrm{n}, \%, 95 \% \mathrm{Cl})\end{array}$ & $\begin{array}{c}\text { Effective } \\
\text { (n, \%, 95\%cl) }\end{array}$ & $\begin{array}{l}\text { Clinical evidence } \\
\text { (n, } \%, 95 \% \mathrm{Cl})\end{array}$ & $\begin{array}{l}\text { Firstly referred } \\
(n, \%, 95 \% C l)\end{array}$ & $\begin{array}{c}\text { Effective } \\
\text { (n, \%, 95\%cl) }\end{array}$ & $\begin{array}{l}\text { Clinical evidence } \\
\text { (n, \%,95\%Cl) }\end{array}$ & $\begin{array}{l}\text { Firstly referred } \\
\text { (n, \%,95\%Cl) }\end{array}$ & $\begin{array}{c}\text { Effective } \\
\text { (n, \%,95\%cl) }\end{array}$ & $\begin{array}{l}\text { Clinical evidence } \\
\text { (n, \%,95\%Cl) }\end{array}$ \\
\hline \multirow[t]{2}{*}{ Andrological examination } & $36 / 197(18.3)$ & $28 / 197(14.2)$ & $17 / 28(60.7)$ & $18 / 49(36.7)^{*}$ & $18 / 49(36.7)^{*}$ & $13 / 18(72.2)$ & $18 / 148(12.2)$ & $10 / 148(6.8)$ & $4 / 10(40.0)$ \\
\hline & $13.5-24.3$ & $10.0-19.8$ & $42.4-76.5$ & $24.6-50.8$ & $24.6-50.8$ & $48.8-87.8$ & $7.6-18.5$ & $3.6-12.1$ & $16.7-68.8$ \\
\hline \multirow[t]{2}{*}{ Varicocele } & $39 / 197(19.8)$ & $39 / 197(19.8)$ & $37 / 39(94.9)$ & $9 / 49(18.4)$ & $9 / 49(18.4)$ & $9 / 9(100)$ & $30 / 148(20.3)$ & $30 / 148(20.3)$ & $28 / 30(93.3)$ \\
\hline & $14.8-26.0$ & $14.8-26.0$ & $82.2-99.5$ & $9.8-31.6$ & $9.8-31.6$ & $65.5-100$ & $14.5-27.5$ & $14.5-27.5$ & $77.6-99.2$ \\
\hline \multirow[t]{2}{*}{ Pain testis } & $11 / 197(5.6)$ & $11 / 197(5.6)$ & $10 / 11(90.9)$ & $2 / 49(4.1)$ & $2 / 49(4.1)$ & $2 / 2(100)$ & $9 / 148(6.1)$ & $9 / 148(6.1)$ & $8 / 9(88.9)$ \\
\hline & $3.0-9.8$ & $3.0-9.8$ & $60.1-99.9$ & $0.4-14.5$ & $0.4-14.5$ & $29.0-100$ & $3.1-11.3$ & $3.1-11.3$ & 54.3-99.9 \\
\hline \multirow[t]{2}{*}{ Other organic diseases } & $56 / 197(28.4)$ & $46 / 197(23.4)$ & $42 / 46$ (91.3) & $16 / 49(32.7)$ & $14 / 49(28.6)$ & $12 / 14(85.7)$ & $40 / 148(27.0)$ & $32 / 148(21.6)$ & $30 / 32(93.8)$ \\
\hline & $22.6-35.1$ & $18.0-30.0$ & 79.1-97.1 & $21.2-46.7$ & $17.8-42.5$ & $58.8-97.2$ & $20.5-34.7$ & $15.7-29.0$ & $78.8-99.3$ \\
\hline \multirow[t]{2}{*}{ Dysmorphophobias } & $17 / 197(8.6)$ & $33 / 197(16.8)$ & $5 / 33(15.2)$ & $3 / 49(6.1)$ & $5 / 49(10.2)$ & $1 / 5(20.0)$ & $14 / 148(9.5)$ & $28 / 148(18.9)$ & $4 / 28(14.3)$ \\
\hline & $5.4-13.5$ & $12.2-22.6$ & $61.7-31.4$ & $1.5-17.5$ & $4.0-22.2$ & $2.0-64.0$ & $5.6-15.4$ & $13.4-26.0$ & 5.1-32.1 \\
\hline \multirow[t]{2}{*}{ Infections and contraception } & $9 / 197(4.6)$ & $4 / 197(2.0)$ & $4 / 4(100)$ & - & - & - & $9 / 148(6.1)$ & $4 / 148(2.7)$ & $4 / 4(100)$ \\
\hline & $2.3-8.6$ & $0.6-5.3$ & $45.4-100$ & & & & $3.1-11.3$ & $0.8-7.0$ & $45.4-100$ \\
\hline \multirow[t]{2}{*}{ Sexual dysfunctions } & $24 / 197(12.2)$ & $31 / 197(15.7)$ & $26 / 31(83.9)$ & - & - & - & $24 / 148(16.2)$ & $31 / 148(21.0)$ & $26 / 31(83.9)$ \\
\hline & $8.3-17.5$ & $11.3-21.5$ & $66.9-93.4$ & & & & $11.1-23.1$ & 15.3-28.2 & $66.9-93.4$ \\
\hline \multirow[t]{2}{*}{ Other: trauma, testicular torsion, etc } & $5 / 197(2.5)$ & $5 / 197(2.5)$ & $5 / 5(100)$ & $1 / 49(2.0)$ & $1 / 49(2.0)$ & $1 / 1(100)$ & $4 / 148(2.7)$ & $4 / 148(2.7)$ & $4 / 4(100)$ \\
\hline & $0.9-6.0$ & $0.9-6.0$ & $51.1-100$ & $<0.1-11.7$ & $<0.1-11.7$ & $16.8-100$ & $0.8-7.0$ & $0.8-7.0$ & $45.4-100$ \\
\hline
\end{tabular}


frenulum, 3/13 retractile testis, 1/13 hypospadias) compared with Group B (4/10 subjects: 1/4 varicocele, 1/4 sub-phimosis, 2/4 short frenulum).

2. Varicocele: $9 / 49$ subjects in Group A and 30/148 subjects in Group B referred to us for a suspected varicocele. During the andrological examination we observed varicocele in all the Group A subjects (6/9 of grade I, $3 / 9$ of grade II), and in 28/30 Group B subjects ( $9 / 28$ of grade I, $16 / 28$ of grade II, $3 / 28$ of grade III).

3. Testis pain: this problem was observed in 2/49 subjects in Group A and 9/148 subjects in Group B. Specifically, two subjects in Group A showed epididymal hypertrophy; regarding Group B, 8/9 subjects had epididymal hypertrophy, while the remaining subject had grade II varicocele.

4. Other organic diseases: in 12/14 Group A subjects, we observed clinical evidence of organic disease (4/12 phimosis, 3/12 gynaecomastia, 3/12 retractile testis, 1/12 cryptorchidism and 1/12 pubertal delay). Moreover, in 30/32 Group B subjects, we observed clinical confirmation of organic disease (6/30 short frenulum, 5/30 sub-phimosis, 3/30 gynaecomastia, 4/30 retractile testis, 2/30 cryptorchidism, 4/30 hypogonadotropic hypogonadism, 2/30 penis recurvatum, 3/30 phimosis and $1 / 30$ adrenogenital syndrome).

5. Dysmorphophobias: in Group A, only 1/5 subject showed adipomastia. Moreover, in Group B, only 4/28 subjects showed any clinical evidence of a condition (3/4 penis in peri-pubic fat and 1/4 adipomastia).

6. Infections and contraception: these problems only concerned Group B. In particular, 1/4 subjects showed gland inflammation, $1 / 4$ secretion in the urethral meatus, 1/4 condylomas; finally, $1 / 4$ subjects needed information about contraception.

7. Sexual dysfunction: these problems only concerned Group B. The diagnosis was made by using specific questionnaires (IIEF-5 and PEDT). In particular, premature ejaculation was observed in 16/26 subjects, erectile dysfunction in $8 / 26$ subjects and anejaculation and/or anorgasmia in $2 / 26$ subjects.

8. Other: in Group A we observed a reduced testicular volume (post trauma) in one subject; in Group B we observed a reduced testicular volume post testicular torsion (1/4), post orchitis (1/4), post trauma (2/4).

All subjects were directed to the appropriate and specific diagnostic/therapeutic pathways.

\section{Discussion}

This study considered the prevalence of male adolescents referred to our Andrology Unit.

The subjects of this study were divided into two groups, according to age.

Of the $6.9 \%$ of adolescents found, $5.2 \%$ were regarded subjects of post-pubertal age while only $1.7 \%$ were regarded subjects of pre- and peri-pubertal age.

According to the literature (6-8), the main reasons that prompt adolescents to carry out this kind of examination are: suspicion of organic diseases (28.4\%), varicocele $(19.8 \%)$ and preventive andrological check-up (18.3\%). However, our study found that other impor- tant factors may prompt the decision to undergo such an examination.

Critical analysis of our results showed that $11.9 \%$ of all subjects included in this study corrected the stated motivation for their andrological assessment during the anamnestic interview. This concerned mainly Group B subjects, aged $\geq 15$ years. This is perhaps because parents reported the problems of the younger subjects.

We noted that subjects found some difficulties in explaining to the andrologist their worries regarding sexual dysfunctions and dysmorphophobias.

These problems were first reported in the context of a preventive andrological examination or organic disease or a suspicion of infection, but it would seem that a different worry could be the real prompt for an examination in many cases.

An interesting finding concerned sexual dysfunctions. In fact, in about $15 \%$ of the cases, it was necessary only to explain the real definition of a condition to reassure a subject that there was no real problem. For example, some subjects reported premature ejaculation (PE), with sexual intercourse lasting about 10 minutes. Instead, PE can be defined as being Intravaginal Ejaculation Latency Time (IELT) of less than 1 minute), which is quite different from the subject's perception. Furthermore, no problem was observed in $84 \%$ of subjects who had reported dysmorphophobia.

A very important point to underline is that the andrological check-up showed itself to be extremely useful in detecting clinical alterations (such as phimosis, gynaecomastia, retractile testis, cryptorchidism and pubertal delay) in more than $60 \%$ of subjects. It is for this reason that every effort should be made to ensure that adolescent males get a chance to undergo an andrological screening. The limit of the present work is the single-centre retrospectively based form.

In conclusion, in Italy, the prevalence of adolescents among the males referred to an Andrology Unit for assessment is very low. This may be due to the fact that here the professional figure of the andrologist is little known among young males and it is therefore essential to promote awareness of andrological examinations through mass media and school campaigns for prevention $(2,5,12)$. Early diagnosis of andrological diseases is crucial so as to prevent later problems in reproductive function. Finally, sexual education during adolescence is also very important because it could help to reduce many psycho-sexual problems.

\section{AUTHORS' ROLE}

FM and RM conceived the study. SO and RM analysed the data drafted the manuscript. All authors contributed to the data collection and/or interpretation, and provided a critical revision of the manuscript.

\section{REFERENCES}

1. Sixty-fourth World Health Assembly. Resolution WHA 64.28: Youth and health risks. Geneva, World Health Organization, 2011.

2. Mondaini N, Silvani M, Zenico T, et al. Genital diseases aware- 
ness in young male students: Is information necessary to protect them? Arch Ital Urol Androl. 2013; 85:14-9.

3. Campodonico F, Michelazzi A, Capurro A, Carmignani G. Andrologic disease detected during army medical visit. Arch Ital Urol Androl. 2003; 75:205-7.

4. Hadziselimovic F, Herzog B. Andrological problems in adolescence. Ther Umsch. 1994; 51:305-13.

5. Foresta C, Garolla A, et al. Anthropometric, penile and testis measures in post-pubertal Italian males. J Endocrinol Invest. 2013; 36:287-92.

6. Pereira NM. Phimosis, hydrocele and varicocele. 3 frequent pathologies in the male child and adolescent. Acta Med Port. 1999, 12:137-43.

7. Serefoglu EC, Saitz TR, La Nasa JA Jr, Hellstrom WJ. Adolescent varicocoele management controversies. Andrology. 2013; 1:109-15.
8. Fast AM, Deibert CM, Van Batavia JP, et al. Adolescent varicocelectomy: does artery sparing influence recurrence rate and/or catch-up growth? Andrology. 2014; 2:159-64.

9. Maggi M, Buvat J. Standard operating procedures: pubertas tarda/delayed puberty--male. J Sex Med. 2013; 10:285-93.

10. Foresta C, Garolla A, Zuccarello D, et al. Human papillomavirus found in sperm head of young adult males affects the progressive motility. Fertil Steril. 2010; 93:802-6.

11. Delfino M, Elia J, Imbrogno $N$, et al. Testicular adrenal rest tumors in patients with congenital adrenal hyperplasia: prevalence and sonographic, hormonal, and seminal characteristics. J Ultrasound Med. 2012; 31:383-8.

12. Valkenburg PM, Peter J. Online communication among adolescents: an integrated model of its attraction, opportunities, and risks. J Adolesc Health. 2011; 48:121-7.

\section{Correspondence}

Soraya Olana, MD

soraya.olana@gmail.com

Rossella Mazzilli, MD (Corresponding Author)

rossella.mazzilli@uniromal.it

Michele Delfino, MD

micheledelfino@libero.it

Virginia Zamponi, MD

virginia22.zamponi@gmail.com

Cristina Iorio, MD

cristina.iorio90@gmail.com

Fernando Mazzilli, MD

fernando.mazzilli@uniromal.it

Sant'Andrea Hospital, University of Rome "Sapienza", Rome, Italy 